\title{
Competencies and higher education: evidences and returns. The TECO project
}

\author{
Alberto Ciolfi, Annalisa Di Benedetto
}

National Agency for the evaluation of Universities and Research Institutes (ANVUR), Italy

\begin{abstract}
The aim of this work is to present the state of progress and the main features of the TECO (TEst of COmpetence) project, promoted by the (Italian) National Agency for the Evaluation of Universities and Research Institutes with the aim to assess students' learning outcomes in the higher education contest. The results of the 2017-2018 TECO survey (which involved voluntarily over 12,500 nursing, physiotherapy and medical radiology students), showed that attending a university programme makes a difference in development of some competencies, especially for the disciplinary sphere. The analysis will focus on the connections between the characteristics of the students at the beginning of their study career and the achieved level of tested competences.
\end{abstract}

The return of the test results to the students and study programmes' coordinators will be presented and discussed, considering their possible uses in a self-assessment perspective.

TECO results and the new indicators that will be originated from this project could prove to be reliable tools for university programmes self-assessment, encouraging the use of evidence-based strategies for higher education improvement.

Keywords: higher education assessment; self-assessment tools; learning outcomes indicators; generic competencies; disciplinary competencies. 


\section{Introduction}

The Test of Competence (TECO) project, promoted by the National Agency for the Evaluation of Universities and Research Institutes (Agenzia Nazionale per la Valutazione del sistema Universitario e della Ricerca - ANVUR), has the aim to develop indicators about the students' learning outcomes, as part of the teaching \& learning assessment included in the National accreditation system (called Autovalutazione - Valutazione periodica - Accreditamento, AVA) of study programmes and universities. Those indicators are meant to be used as tools for the self-assessment activities and to inform the governance of higher education institutions.

In the following, the TECO project will be presented, as well as evidences from the last and so far, the broader - survey (2017-2018). Finally, the return of results to the participating students and study programmes will be described.

\section{TECO project: aims and instruments}

TECO project has been developed in Italy by ANVUR since 2013. The Agency, among its duties (established by its institutive Presidential Decree - DPR 76/2010 - and the subsequent decrees issued by the Italian Ministry of Education, University and Research), received the mandate to define new indicators about the students' learning outcomes, as part of the teaching evaluation scheme that includes self-assessment, periodic evaluation, and accreditation of study programmes and universities (AVA). In this framework TECO project aims to the assessment of students' competences, as a proxy for the learning outcomes.

The first TECO trials, between 2013 and 2015, availed for the evaluation of Italian undergraduates' learning outcomes of the CLA + test ${ }^{1}$. These experiences bared several shortcomings: a selection bias, weak interrater correlations and weak correlations between open and closed questions rates, in addition to the high cost of the procedure (see Ciolfi et al., 2016; Damiani et al., 2016; 2017). Thus, in 2016 ANVUR revised the whole project: from the domains of assessed competences to the methodology adopted.

To date, two branches of TECO have been developed, pointing toward the assessment of generic (TECO-T, where $\mathrm{T}$ stands for trasversale) and disciplinary (TECO-D, with D standing for disciplinare) competencies. Generic and disciplinary competences are conceived in a broad perspective, in line with the Definition and Selection of Competencies

\footnotetext{
${ }^{1}$ The CLA+ test, produced by the Council for Aid to Education (CAE), is meant to measure the students' performance on analysis and problem solving, scientific and quantitative reasoning, critical reading and evaluation, and critiquing an argument, in addition to writing mechanics and effectiveness. It was administered twice: during 2013 in collaboration with 12 universities and during 2015 in collaboration with 24 universities (see Ciolfi et al. 2016; Ciolfi \& Sabella, 2017).
} 
(DeSeCo): «a competence is more than just knowledge or skills. It involves the ability to meet complex demands, by drawing on and mobilising psychosocial resources (including skills and attitudes) in a particular context» (Rychen \& Salganik, 2003).

Undergraduates can develop generic competencies during their university career, independently of the specific study programme. The TECO-T items are produced in house by ANVUR, in collaboration with academic experts and in the wake of several international studies $^{2}$. Disciplinary competencies are conversely strictly linked to a given study programme, therefore the related TECO-D are developed by working groups made up of representatives of the scientific societies of the discipline ${ }^{3}$.

A strong impulse to the project has been provided in 2017, when the progress tests already used by three healthcare profession study programmes (Nursing, Physiotherapy and Medical radiology) voluntarily underwent a validation analysis by ANVUR and a subsequent item revision, to be adopted as three different TECO-Ds (one for each programme). From late 2017 until early 2018, the TECO-D of these three study programmes was delivered to about 12,500 students from 27 Universities ${ }^{4}$.

Accordingly to the main purposes of the project, the value-added approach has been adopted - whereby both the competences of ingoing (first-year students) and outgoing (third-year students) first cycle university students are assessed. In perspective, each coordinator of a study programme should consider not only its students' absolute results in comparison with those achieved by students from other universities, but also, and more interestingly, the change occurred from the initial conditions.

\footnotetext{
${ }^{2}$ For instance: the Six Subject Survey, the Progress in International Reading Literacy Study (PIRLS), the Trends in International Mathematics and Science Study (FIMMS and TIMSS), the International Civic and Citizenship Education Study (ICCS) endorsed by the International Association for the Evaluating of International Achievement (IEA); the Programme for International Student Assessment (PISA) and the Programme for the International Assessment of Adult Competences (PIAAC), by the Organisation for Economic Co-operation and Development (OECD). Should also be considered the Assessment of Learning Outcomes in Higher Education (AHELO), dedicated to learning outcomes in higher education.

${ }^{3}$ ANVUR supervises each TECO-D working group's activities and provides dedicated methodological and technical support. All the TECO tests undertake a validation procedure, including at least one field trial. The commitment in the project is voluntary.

${ }^{4}$ A total attendance of 12.510 students, of whom 3.993 (31.9\%) carried out the paper and pencil version of the test rather than on the online platform managed by CINECA, an interuniversity consortium that offers support to the research activities through supercomputing and its IT applications.
} 


\section{Evidences on competencies development in higher education}

The 2017-2018 TECO survey, involving students enrolled in Nursing, Physiotherapy and Medical radiology programmes in different universities across the Country, is by far the largest assessment of university students' competences accomplished in Italy to date. In addition to one of the three available TECO-Ds, each of the participants performed also two generic competences tests ${ }^{5}$ : Literacy and Numeracy.

Literacy items ${ }^{6}$ are meant to evaluate the undergraduates' levels of understanding and reflecting competencies on a text with a generic content. Numeracy items ${ }^{7}$ assess undergraduates' levels in logical thinking and solving quantitative problems. Generic competencies scores were calculated considering all the participants'; disciplinary competencies scores were calculated separately for each TECO-D ${ }^{8}$.

The participation to the 2017-18 survey was less extensive for the Nursing programmes, which have usually more students and different locations per programme (see Table 1).

Table 1. Participation to the 2017-18 TECO survey: performed tests by year and discipline, total number of students enrolled in the participating programmes, participation rate

\begin{tabular}{ccccccc}
\hline & \multicolumn{3}{c}{ Performed tests } & \multirow{2}{*}{ Enrolled students } & Partecipation rate \\
\cline { 2 - 5 } & 1 year & 2 year & 3 year & Total & & \\
\hline Nursing & 4,553 & 2,088 & 2,740 & 9,382 & 24,110 & $38.9 \%$ \\
Physiotherapy & 585 & 513 & 659 & 1,757 & 2,680 & $65.6 \%$ \\
Medical radiology & 330 & 221 & 350 & 901 & 1,281 & $70.3 \%$ \\
\hline
\end{tabular}

The following analysis focus on the connections between the identified competences and the characteristics of the students at the beginning of their university studies. In order to reduce the risk of distortions, these analyses consider only the first-year students enrolled in 2017-2018 and the third-year students enrolled in 2015-2016, who have completed all the three parts of the TECO: Literacy, Numeracy and one of the TECO-D (Table 2).

\footnotetext{
${ }^{5}$ For two others ambits the design process was ongoing. At present, the frameworks of Problem Solving (see ANVUR, 2019), and Civics tests have already been defined, with the items of the former to be validated in spring 2019.

${ }^{6}$ The test contains two types of items: the former require participants to complete 10 closed-answer questions after reading a text, in the latter they have to complete a short text with 20 words that are missing (Cloze test), for a total of 30 items.

${ }^{7}$ This test provides for a short text that includes graphs and tables, followed by five questions, an infographic followed by five questions, and 15 short logical reasoning questions, for a total of 25 items

${ }^{8}$ Two parameter IRT models were used. All the scores are standardized on a scale with mean 200 and standard deviation 40 , to simplify the comparison.
} 
Table 2. Complete tests by year and discipline, for the first-year students enrolled in 2017-2018 and the third-year students enrolled in 2015-2016

\begin{tabular}{cccc}
\hline & 1 year & 3 year & Total \\
\hline Nursing & 4,185 & 1,625 & 5,810 \\
Physiotherapy & 422 & 385 & 807 \\
Medical radiology & 241 & 228 & 469 \\
Total & 4,848 & 2,238 & 7,086 \\
\hline
\end{tabular}

Finally, the methods for returning the TECO results to the participating students and to study programmes' coordinators will be presented, discussing the possible uses in a selfassessment perspective.

\subsection{Generic competencies}

From an analysis by cohort, the outcomes on generic competences appear to be narrow but significant (Figure 1; for a more broad analysis see Ciolfi \& Sabella, 2018).

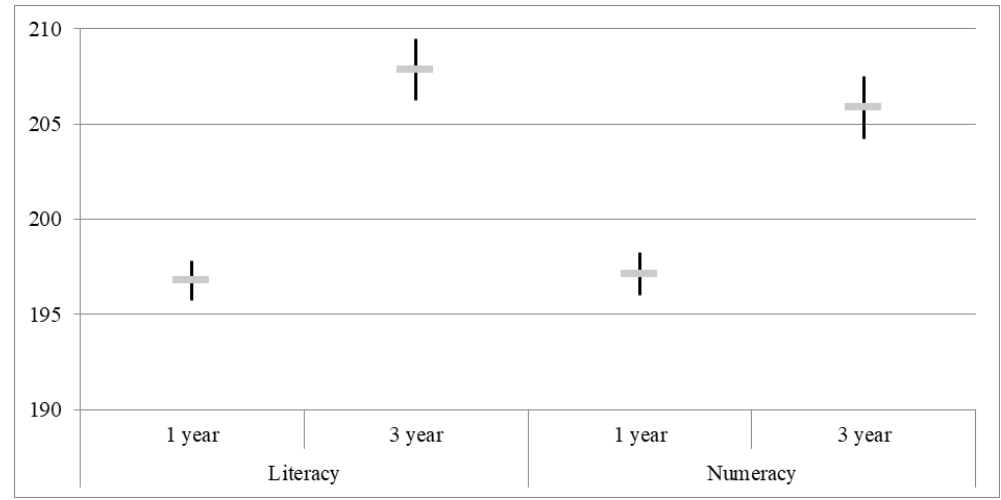

Figure 1. Generic competences scores: mean and confidence interval ( $\tilde{x} \pm$ std.err.) by enrollment year

It is worthy to consider the generic competences in the light of the characteristics of the students at the beginning of their university studies. Further, the disciplinary competence will be examined from the same perspective. The regression models in Table 3 contemplate as possible explicative factors the enrolment year, the gender, the age, the type of high school attended (School of origin), the high school's final grade and the social-cultural status 9 .

\footnotetext{
${ }^{9}$ Social-cultural status index, inspired to the Economic, Cultural, and Social Status (ESCS) used in the OECD-PISA reports (even if without the home possession dimension). It is obtained using a principal component analysis on the parents' higher occupational
} 
Some of these evidences could lead to a cumulative advantage hypothesis ("the rich get richer, the poor get poorer") ${ }^{10}$, which however would require a more detailed study on longitudinal data by cohort. The effect of the enrolment year is accompanied by other significant effects related to the gender and the previous education studies (for Numeracy, the social-cultural status also).

Table 3. Regression models for Literacy and Numeracy scores by: enrolment year, gender, age, school of origin, final grade and social-cultural status - coefficients, sig., N. and R-squared

\begin{tabular}{llcc}
\hline & & Literacy & Numeracy \\
\hline Enrollment year & $3 / 1$ & $8,570^{* * *}$ & $8,791 * * *$ \\
Gender & Female / Male & $-4,598 * * *$ & $-3,412^{* * * *}$ \\
Age & $20-21 /$ under 19 & $-1,531$ & $-3,412^{*}$ \\
& $22-23 /$ under 19 & $-0,022$ & $-6,277 * *$ \\
& over 24 / under 19 & $-1,66$ & $-9,589 * * *$ \\
School of origin & High school / Tecnical school & $8,129 * * *$ & $8,696 * * *$ \\
School final grade & High / Low & $7,789 * * *$ & $8,527 * * *$ \\
Social-cultural status & & 0,967 & $1,538 * *$ \\
Constant & & $194,95 * * *$ & $206,631 * * *$ \\
\hline & $\mathrm{N}$ & 4.584 & 4.584 \\
& $\mathrm{R}-\mathrm{squared}$ & 0,0345 & 0,0624 \\
\hline
\end{tabular}

$* p<.05, * * p<.01, * * * p<.001$

\subsection{Disciplinary competencies}

The effect of university studies on disciplinary competences results significant and far more consistent, if compared with the effect on the generic competences scores (see Figure 2).

\footnotetext{
status (scored according to Ganzeboom \& Treiman, 1996) and the parents' higher number of year of instruction (the proportion of variance explained by the extracted component is $70.7 \%$ ).

10 This hypothesis would diverge from earlier works concerning the TECO administration of the CLA+ test (Ciolfi \& Sabella, 2017).
} 


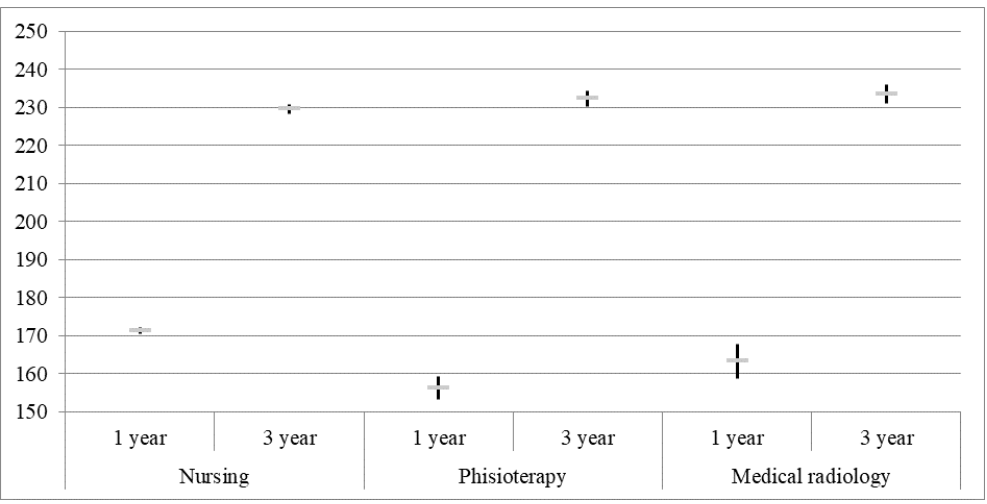

Figure 2. Disciplinary competences scores: mean and confidence interval ( $\tilde{x} \pm$ std.err.) by enrollment year

The regression models in Table 4 point out, besides the relevance of the enrolment year, also the lack of significance of almost all the other factors, with few exceptions (i.e. school final grade and age for Nursing; school final grade and gender for Medical radiology).

These results are extremely encouraging, especially considering the wide effect of higher education studies, regardless of the students' characteristics at the beginning of their course. As mentioned above, the TECO-D for nursing, physiotherapy and medical radiology study programmes were delivered because the corresponding working groups were the first to join the project. Currently, other disciplinary working groups, such as literature, philosophy, pedagogy, psychology started developing a TECO-D. 
Table 4. Regression models for the disciplinary scores by: enrolment year, gender, age, school of origin, final grade and social-cultural status - coefficients, sig., N. and R squared

\begin{tabular}{llccc}
\hline & & & & Medical \\
& & Nursing & Phisioterapy & radiology \\
\hline Enrollment year & $3 / 1$ & $60,459 * * *$ & $70,159 * * *$ & $66,482 * * *$ \\
Gender & Female / Male & $-2,078$ & 2,989 & $-7,898^{*}$ \\
& 20-21 / under 19 & $4,577 * * *$ & 4,989 & 7,318 \\
Age & 22-23 / under 19 & 0,967 & 4,0129 & 11,411 \\
& over 24 / under 19 & $3,632 *$ & 4,013 & 11,01 \\
School of origin & High school / Technical school & $-0,908$ & 1,043 & 0,708 \\
School final grade & High / Low & $5,835 * * *$ & $-0,380$ & $15,608 * * *$ \\
Social-cultural status & & 0,035 & 3,799 & $-0,884$ \\
Constant & & $67,468 * * *$ & $150,836 * * *$ & $153,264 * * *$ \\
\hline N & & 3.726 & 565 & 293 \\
R-squared & & 0,4514 & 0,6649 & 0,6079 \\
\hline
\end{tabular}

$* \mathrm{p}<.05, * * \mathrm{p}<.01, * * * \mathrm{p}<.001$

\subsection{Return of TECO results}

The results of each TECO survey are made available to all attending students and their study programmes' coordinators. Students receive, on request, their personal results together with clear reference points to compare them (i.e. the mean score obtained by students with a similar profile). The certificate of attendance presents, for Literacy and Numeracy TECO-T: the score obtained the average score of students of the same enrollment year, the average score of students of the same enrollment year and university. For the TECO-D, the row score by topic is presented, along with the reference averages. 
Table 5. Overall reference data for the participating programmes, simplified example table containing only the average score per cohort and study programme

\begin{tabular}{|c|c|c|c|c|c|c|c|c|c|}
\hline \multirow[b]{2}{*}{ Cohort* } & \multicolumn{3}{|c|}{ Nursing } & \multicolumn{3}{|c|}{ Phisioterapy } & \multicolumn{3}{|c|}{ Medical radiology } \\
\hline & Lit. & Num. & Disc. & Lit. & Num. & Disc. & Lit. & Num. & Disc. \\
\hline 1 year, enrolled before 2016 & 208 & 208,8 & 175,9 & 181,2 & 154,3 & 176,4 & 215,2 & 238,8 & 191,3 \\
\hline 1 year, enrolled in 2016 & 207,7 & 223,3 & 167,6 & 188,2 & 192 & 166,4 & 210,2 & 224,8 & 134,1 \\
\hline 1 year, enrolled in 2017 & 206,2 & 220,1 & 159 & 194,8 & 195,3 & 175,3 & 205,9 & 210,6 & 163,2 \\
\hline 2 year, enrolled before 2015 & 189,7 & 213,7 & 204,5 & 187,4 & 195,1 & 216,9 & - & - & - \\
\hline 2 year, enrolled in 2015 & 209,8 & 227,7 & 215,7 & 179,3 & 175,4 & 211,5 & 211,1 & 220,6 & 179,1 \\
\hline 2 year, enrolled in 2016 & 209,6 & 225,9 & 207,9 & 190,7 & 193,7 & 221,2 & 207 & 222,1 & 196,7 \\
\hline 3 year, enrolled before 2014 & 206,6 & 210,3 & 231,3 & 191 & 190,9 & 241,6 & 204,6 & 203,8 & 219 \\
\hline 3 year, enrolled in 2014 & 209,6 & 212,4 & 236,6 & 197 & 191,6 & 242,1 & 217,4 & 226,7 & 241,6 \\
\hline 3 year, enrolled in 2015 & 207,7 & 220,2 & 233 & 197,7 & 194,5 & 236 & 213,8 & 225,8 & 232,3 \\
\hline Total & 206,9 & 219,4 & 203 & 191,9 & 190,7 & 207,6 & 210 & 221,2 & 201,1 \\
\hline
\end{tabular}

*Cohorts that include too few students are obscured out for privacy protection reasons.

Regarding the return of results to study programmes, the goal is to give useful information for self-assessment purposes. Each university receives its own microdata (suitably anonymized and obscured to prevent the identification of students) and a table presenting the overall reference data. The latter are referred to all the participating programmes and are presented by cohort and study programme: the average scores for each competence tested, the average number of correct answers for each thematic area of the disciplinary test and the total number of attendees (see as a simplified example - containing only the average scores - Table 5) are made available.

\section{Conclusions and remarks}

The attendance to a university study programme makes a difference in the development of some competencies, especially for the disciplinary sphere. TECO project results could be reliable tools for university programmes self-assessment, to be used for evidence-based strategies in higher education improvement.

The return of the TECO results aims at helping the programmes' coordinators to initiate or deepen the reflection about the generic competence development, by providing a broader information framework on the profile of their students. The project intends to contribute to 
the analysis of the strengths and weakness of the offered disciplinary training, helping the reflection on the possible improvement interventions, with respect to the planning and implementation of the programmes.

\section{References}

ANVUR (2019). Il problem solving come competenza trasversale: inquadramento e prospettive nell'ambito del progetto TECO, Scuola Democratica, 1/2019, (in press).

Ciolfi, A., Damiani V., Delli Zotti, F., Sabella, M. (2016). La sperimentazione sulla valutazione delle competenze attraverso il test sulle competenze (TECO - 2013 e 2015)», in ANVUR, Rapporto sullo Stato del Sistema Universitario e della Ricerca 2016, Roma, ANVUR, pp. 259-287.

Ciolfi, A., Sabella, M. (2017). Assessing resilience at University. In Proceedings of the 3rd International Conference on Higher Education Advances (pp. 1104-1112). Editorial Universitat Politècnica de València.

Ciolfi, A., Sabella, M. (2018). La rilevazione delle competenze degli studenti: il progetto TECO, in ANVUR, Rapporto sullo Stato del Sistema Universitario e della Ricerca 2018, Roma, ANVUR, pp. 155-166.

Damiani, V., Agrusti, F., Ciolfi, A. (2016). Le prove a risposta aperta della sperimentazione TECO 2015: esplorazione dell'archivio testuale. CADMO, Volume 24, Issue 2, 2016, pp. 105-111; ISSN: 1122-5165.

Damiani, V., Agrusti, F., Ciolfi, A. (2017). Argomentare all'università. Un'analisi delle prove a risposta aperta della sperimentazione TECO 2015; CADMO, 1, 2017; ISSN 1122-5165.

Rychen, D. S., Hersch, S. L. (Eds) (2003). Key Competencies for a Successful Life and a WellFunctioning Society. Cambridge, MA: Hogrefe \& Huber. 